Consultant for: Eli Lilly and Company, J. Rancourt Employee of: Eli Lilly and Company, C. Dickson Employee of: Eli Lilly and Company, Y. Isaka Employee of: Eli Lilly and Company, L. Chen: None declared, T. Carmack Employee of: Quintiles, D. Hyslop Employee of: Eli Lilly and Company, D. Muram Employee of: Eli Lilly and Company, W. Macias Employee of: Eli Lilly and Company, J. Bradley Employee of: Eli Lilly and Company, E. Keystone Grant/research support from: Abbott, Amgen, AstraZeneca, BMS, Hoffmann-LaRoche, Janssen, Eli Lilly and Company, Novartis, Pfizer, Sanofi-Aventis,UCB, Consultant for: Abbott, AstraZeneca, Biotest, BMS, Crescendo Biosciene, Hoffmann-LaRoche, Genentech, Janssen, Eli Lilly and Company, Merck, Pfizer, UCB, Speakers bureau: Abbott, AstraZeneca, BMS Canada, Hoffmann-laRoche, Janssen, Pfizer, UCB, Amgen

DOI: 10.1136/annrheumdis-2017-eular.1335

\section{FRI0093 CAROTID ATHEROSCLEROSIS IS ASSOCIATED WITH DISEASE ACTIVITY AND BONE MINERAL DENSITY IN RHEUMATOID ARTHRITIS}

J.W. Kang, E.S. Lee, J.S. Eun, J.H. Kim, J.Y. Kang, G.B. Bae, N.R. Kim, S.J. Lee, E.J. Nam, Y.M. Kang. Kyungpook National University School of Medicine, Daegu, Korea, Republic of

Background: Rheumatoid arthritis (RA) is a chronic inflammatory disease which causes juxta-articular and generalized bone loss. Several studies revealed that bone mineral density (BMD) is associated with atherosclerosis.

Objectives: In the present study, we investigated the association between BMD and RA disease activity and the carotid atherosclerosis in RA patients based Kyungpook National University Hospital Atherosclerosis Risk in Rheumatoid Arthritis (KARRA) cohort study.

Methods: A total of 323 patients with RA, who performed dual-photon x-ray absorptiometry and carotid ultrasound, were included. We assessed RA disease activity, risk factors for atherosclerosis including hypertension, diabetes mellitus and dyslipidemia, presence of carotid plaque, carotid intima-media thickness (IMT), and BMD. BMD was measured at the lumbar spine (L-spine, L1-L4), femur neck (total femur neck) and distal forearm (total radius), and low BMD was defined as a $\mathrm{T}$ score of -1.0 or less.

Results: The BMD in the L-spine, femur, and radius was significantly lower in patients with carotid plaques $(n=152)$, compared to patients without plaques $(\mathrm{n}=171)\left(1.014 \mathrm{~g} / \mathrm{cm}^{2} \pm 0.21\right.$ vs. $1.066 \mathrm{~g} / \mathrm{cm}^{2} \pm 0.18, p=0.016$ for L-spine; 0.816 $\mathrm{g} / \mathrm{cm}^{2} \pm 0.16$ vs. $0.863 \mathrm{~g} / \mathrm{cm}^{2} \pm 0.13, p<0.001$ for femur; $0.542 \mathrm{~g} / \mathrm{cm}^{2} \pm 0.13 \mathrm{vs}$. $0.603 \mathrm{~g} / \mathrm{cm}^{2} \pm 0.12, p<0.001$ for radius). The frequency of low BMD in these areas was also higher in patients with carotid plaques, compared to patients without plaques $(52.7 \%$ vs. $47.5 \%, p=0.045$ for L-spine; $56.0 \%$ vs. $44.0 \%, p=0.001$ for femur; $60.6 \%$ vs. $39.4 \%, p<0.001$ for radius). Carotid IMT showed a significant difference between patients with low BMD and those with normal BMD $(0.84$ $\mathrm{mm} \pm 0.14$ vs. $0.80 \mathrm{~mm} \pm 0.19, p=0.025$ for L-spine; $0.83 \mathrm{~mm} \pm 0.15$ vs. 0.80 $\mathrm{mm} \pm 0.18, p=0.045$ for femur; $0.85 \mathrm{~mm} \pm 0.15$ vs. $0.77 \mathrm{~mm} \pm 0.18, p<0.001$ for radius). In subgroup analysis, patients with the highest IMT quartile had a significantly lower BMD in all the regions than those with the lowest IMT quartile ( $61.2 \%$ vs. $37.7 \%, p=0.004$ for L-spine; $59.5 \%$ vs. $35.1 \%, p=0.003$ for femur; and $71.4 \%$ vs. $28.6 \%, p<0.001$ for radius). Multivariate logistic regression analysis demonstrated that $\mathrm{BMD}$ at radius (OR 4.995, 95\% $\mathrm{Cl}[1.067-10.276], p<0.001)$, DAS28-ESR (OR 1.906, 95\% Cl [1.042-3.046], $p=0.036$ ), and dyslipidemia (OR $2.334,95 \% \mathrm{Cl}[1.164-3.156], p=0.02)$ were risk factors for presence of carotid plaques.

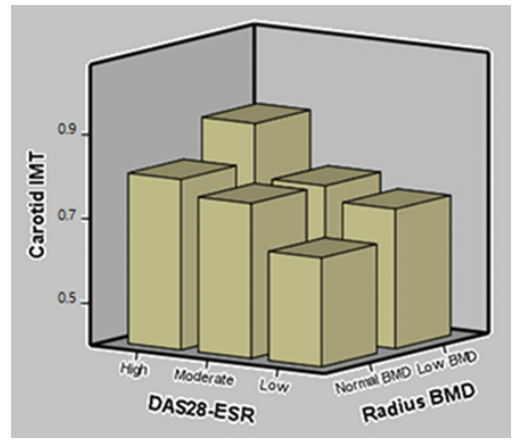

Conclusions: The present study showed that carotid atherosclerosis was influenced by both disease activity and impaired bone health. References:

[1] Im CH et al. Inflammatory burden interacts with conventional cardiovascular risk factors for carotid plaque formation in rheumatoid arthritis. Rheumatology (Oxford). 2015 May;54(5):808-15.

Disclosure of Interest: None declared

DOI: 10.1136/annrheumdis-2017-eular.6387

\section{FRI0094 TIME TO AND FACTORS ASSOCIATED WITH INITIATION OF BIOLOGICAL THERAPY WITH DISEASE-MODIFYING ANTIRHEUMATIC DRUGS IN PATIENTS WITH RHEUMATOID ARTHRITIS IN COLOMBIA}

J.E. Machado-Alba, L.F. Calvo-Torres, A.M. Bañol-Giraldo, S. Garcia-Betancurt on behalf of Grupo de Investigación en Farmacoepidemiología y

Farmacovigilancia. Universidad Tecnológica de Pereira- Audifarma S.A. Grupo de Investigación en Farmacoepidemiología y Farmacovigilancia, Universidad Tecnológica de Pereira-Audifarma S.A, Pereira, Colombia

Background: Rheumatoid arthritis (RA) treatment is usually done with nonbiological disease-modifying antirheumatic drugs (DMARDs), but the addition of a biological DMARD can be necessary. Biological drug therapy is usually prescribed following failure to achieve remission of the morbidity with one or more non-biological DMARDs. However, there is the possibility of using them as a first line in the initial phase, which there is the possibility of potentially altering its course or even reverting it to normality.

Objectives: To determine the time Colombian patients with rheumatoid arthritis (RA) are treated with non-biological disease-modifying antirheumatic drugs (DMARDs) before changing to biological therapy.

Methods: A retrospective cohort study that collected information about the start of antirheumatic treatment in patients of all ages with a diagnosis of RA until the change to biological DMARD therapy. Survival analysis using Kaplan-Meier curves, from 1 January 2007 until 31 December 2013 by SPSS 23.0 for Windows, was made.

Results: A total of 3880 patients $(75.3 \%$ women) with a mean age of 51.3 years started non-biological DMARDs. After 5 years, 234 patients $(6.0 \%)$ initiated biological DMARD therapy in $17.5 \pm 13.9$ months. Differences in the socio demographic and pharmacological characteristics between the two groups of treatment are shown in the table 1. The use of glucocorticoids was associated with a greater risk of biological DMARD initiation (OR: $2.49 ; 95 \% \mathrm{Cl}: 1.658-3.732$; $\mathrm{p}<0.001$ ), while the use of methotrexate (OR: $0.04 ; 95 \% \mathrm{Cl}: 0.014-0.108$; $\mathrm{p}<0.001$ ) and chloroquine (OR: $0.13 ; 95 \% \mathrm{Cl}: 0.092-0.187 ; \mathrm{p}<0.001$ ) reduced the risk of initiation.

\begin{tabular}{|c|c|c|c|c|}
\hline Variables & $\begin{array}{l}\text { Non biological } \\
\text { DMARDs } \\
\text { (n: } 3646 \text { ) }\end{array}$ & $\%$ & $\begin{array}{l}\text { Biological } \\
\text { DMARDs } \\
\text { (n: 234) }\end{array}$ & $\%$ \\
\hline \multicolumn{5}{|l|}{ Sociodemographic } \\
\hline Aged (mean $\pm S D)$ & $52.2 \pm 14.8$ & & $51.2 \pm 16.2$ & \\
\hline Sex (Male/Female, \%) & $74 / 160$ & $31.6 / 68.4$ & $884 / 2762$ & $24.3 / 75.7$ \\
\hline Women > 55 años & 1364 & 37.4 & 79 & 33.8 \\
\hline Men $>45$ ańos & 580 & 15.9 & 46 & 19.6 \\
\hline \multicolumn{5}{|l|}{ Initial therapy } \\
\hline Chloroquine & 1485 & 40.7 & 44 & 18.8 \\
\hline Sulfasalazine & 945 & 25.9 & 0 & 0 \\
\hline Methotrexate & 493 & 13.5 & 4 & 1.7 \\
\hline Azatriopine & 300 & 8.2 & 21 & 9.0 \\
\hline Cyclophosphamide & 117 & 3.2 & 9 & 3.8 \\
\hline Cyclosporine & 112 & 3.1 & 8 & 3.4 \\
\hline Others & 59 & 1.6 & 4 & 1.7 \\
\hline \multicolumn{5}{|l|}{ Comedication } \\
\hline Glucocorticoids & 2183 & 59.9 & 199 & 85.0 \\
\hline Antihypertensives & 582 & 16.0 & 52 & 22.2 \\
\hline Diuretics & 281 & 7.7 & 19 & 8.1 \\
\hline Hipolipemiants & 414 & 11.3 & 33 & 14.1 \\
\hline Antiplatelets & 298 & 8.2 & 20 & 8.5 \\
\hline Antidiabetics & 170 & 4.7 & 11 & 4.7 \\
\hline $\begin{array}{l}\text { Nonsteroidal anti-inflammatory } \\
\text { drugs }\end{array}$ & 298 & 8.2 & 34 & 14.5 \\
\hline Antiulcer drugs & 623 & 17.1 & 91 & 38.9 \\
\hline Thyroid hormone & 200 & 5.5 & 21 & 9.0 \\
\hline Vitamin D and Calcium & 283 & 7.8 & 43 & 18.4 \\
\hline
\end{tabular}

Conclusions: After 5 years of non-biological DMARD therapy, $6.0 \%$ of people with RA started biological DMARDs. Receiving glucocorticoids, having any comedication, being treated in Bogota City or cities of the Colombian Atlantic coast affected the probability of switching to biological therapy in these patients. References:

[1] Nam JL, Emery P. Is there a place for initial treatment with biological DMARDs in the early phase of RA? Best Pract Res Clin Rheumatol. 2013;27(4):537-54

[2] Emery P, Breedveld FC, Hall S, Durez P, Chang DJ, Robertson D, et al. Comparison of methotrexate monotherapy with a combination of methotrexate and etanercept in active, early, moderate to severe rheumatoid arthritis (COMET): a randomised, double-blind, parallel treatment trial. Lancet. 2008;372(9636):375-82.

[3] Tak PP, Rigby WF, Rubbert-Roth A, Peterfy CG, van Vollenhoven RF, Stohl W, et al. Inhibition of joint damage and improved clinical outcomes with rituximab plus methotrexate in early active rheumatoid arthritis: the IMAGE trial. Ann Rheum Dis. 2011;70(1):39-46.

Acknowledgements: To Universidad Tecnológica de Pereira and Audifarma S.A.

Disclosure of Interest: None declared

DOI: 10.1136/annrheumdis-2017-eular.4986 